\title{
Correspondence
}

\section{Symptomatic zinc deficiency in a breast-fed infant}

Sir,

We were in the process of preparing a report on acrodermatitis in exclusively breast-fed infants when the article by Aggett et al. ${ }^{1}$ was published. Unlike them we did not have the benefit of zinc uptake and metabolic balance studies, but our case supports their contention that human breast milk does not protect completely against symptomatic zinc deficiency, and it questions Duncan and Hurley's ${ }^{2}$ suggestion that there is a factor in breast milk which facilitates the absorption of zinc.

\section{Case report}

A 6-month-old girl presented with a history of failure to thrive since age 2 months with irritability, diarrhoea, and a skin rash. The rash consisted of crops of blisters with thickened areas of skin particularly in the perioral region, scalp, soles of the feet, and fingers. The appearance was typical of acrodermatitis enteropathica. Diarrhoea was mild to moderate with 3 loose, greenish, watery stools each day.

She had been born at an alleged 34 weeks' gestation with a birthweight of $2.02 \mathrm{~kg}$ and had been breast fed from the start. Initially she was admitted to another hospital and was investigated there for her skin condition. A diagnosis of acrodermatitis was considered but not confirmed partly because she had been wholly breast fed and, perhaps, because of difficulty in deciding whether the serum zinc level $(6.4 \mu \mathrm{mol} / \mathrm{l})$ was normal.

When admitted under our care she was 6-months old and had been exclusively breast fed. Investigations done were full blood count, neutrophil function test, stool culture, calcium, magnesium, and alkaline phosphatase, and all these were normal. However, a plasma zinc level was $5 \cdot 2 \mu \mathrm{mol} / 1$ (normal, as quoted by Aggett et al. ${ }^{1}$ is 11-24 $\mu \mathrm{mol} / 1)$.

After one week's treatment with oral zinc sulphate 45 $\mathrm{mg}$, three times daily, the skin lesions cleared, she started to gain weight, and the diarrhoea stopped. After treatment the plasma zinc level was $15.4 \mu \mathrm{mol} / \mathrm{l}$.

Work done in this unit by Young ${ }^{3}$ showed that plasma zinc levels fall during the early weeks of life, which tallies with the observation of Cavell and Widdowson ${ }^{4}$ that most babies are in negative zinc balance in the first week of life.

The normal cord plasma zinc levels at term were 39 weeks-16.75 $\pm 3 \cdot 14 \mu \mathrm{mol} / 1,40$ weeks-15.1 $\pm 2 \cdot 88$ $\mu \mathrm{mol} / 1$, and 41 weeks $-14.45 \mu \mathrm{mol}$.

Maternal levels of zinc tend to be lower, but there was an interesting difference which related to the gender of the infant. Those mothers producing girls had plasma zinc levels of $9.57 \pm 1.55 \mu \mathrm{mol} / \mathrm{l}$, whereas mothers producing boys had a mean level of $9.04 \pm 2.01 \mu \mathrm{mol} / \mathrm{l}$, the difference being statistically significant $(\mathrm{P}<0.001)$.

By these standards of serum zinc levels our infant had a low plasma zinc level.

Aggett et al. ${ }^{1}$ found that at 17 weeks' lactation the zinc content of breast milk was $8.86 \mu \mathrm{mol} / 1$. Our study gave early lactation levels ranging from 62.5 to $195 \mu \mathrm{mol} / 1$ although the breast milk from the mother of the child reported here was not estimated for zinc.

Before making the diagnosis topical zinc preparations were used liberally on this child and it is likely from the theories of pathogenesis of acrodermatitis that this made little difference to the zinc levels. In Young's study zinc concentration in neonates was compared before and after treatment of nappy rash with zinc preparations. The fact that in most infants the plasma zinc fell suggests that topical applications of zinc even to broken areas of skin do not result in appreciable zinc absorption.

\section{References}

1 Aggett P J, Atherton D J, More J, Davey J, Delves H T, Harries J T. Symptomatic zinc deficiency in a breast-fed, preterm infant. Arch Dis Child 1980; 55: 547-50.

2 Duncan J R, Hurley L S. Intestinal absorption of zinc: a role for a zinc binding ligand in milk. Am J Physiol 1978; 235: E556-9.

3 Young B. A study of the zinc concentration in the plasma and whole blood of mother, newborn infant, and neonate. BSc thesis, University of St Andrews, Fife.

4 Cavell P A, Widdowson E M. Intakes and excretions of iron, copper, and zinc in the neonatal period. Arch Dis Child 1964; 39: 496-501.

S AHMED AND A W BlaIR
Victoria Hospital,
Hayfield Road,
Kirkcaldy, Fife KY2 $5 A H$

\section{Dr Aggett comments:}

This child's clinical response to an oral zinc supplement is certainly consistent with zinc deficiency. I wonder if the effect of withdrawing the supplement was investigated. We have received several reports of similar cases, one of which was a term breast-fed infant, and recently symptomatic zinc deficiency was reported in preterm infants fed a cows' milk formula. ${ }^{1}$ The condition appears to be more common than we had thought and such reports will help to assess the extent and pathogenesis of overt zinc deficiency during infancy and help to prevent it.

\section{Reference}

1 Bonifazi E, Rigillo N, De Simone B, Meneghini C L. Acquired dermatitis due to zinc deficiency in a premature infant. Acta Derm Venereol (Stockholm) 1980; 60, 449-51. 